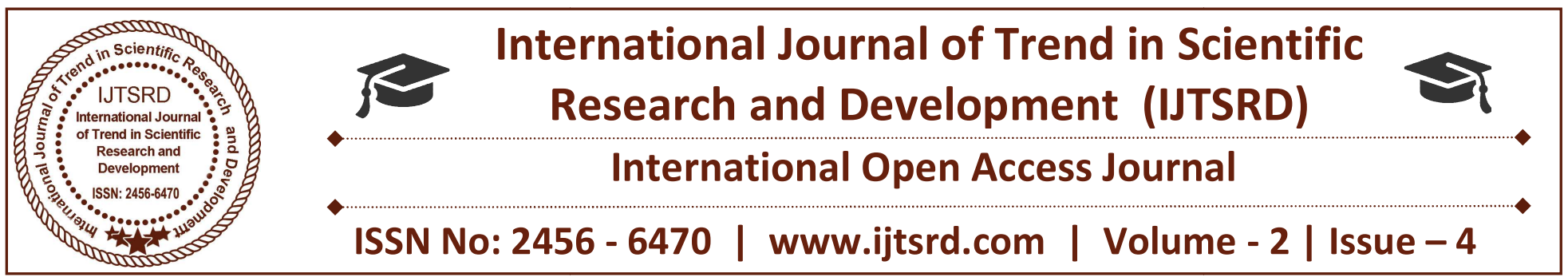

\title{
A Study on Self Concept in Relation to Academic Achievement Among B.Ed Trainees
}

\author{
Ms. B. Deepika ${ }^{1}$, Ms. D. Geetha ${ }^{2}$ \\ ${ }^{1}$ M. Ed Student, ${ }^{2}$ Assistant Professor \\ RVS College of Education Coimbatore, Tamil Nadu, India
}

\begin{abstract}
The purpose of this research was to deter- mine the relationship between the academic self-concept and academic performance. The sample consists of 100 B.Ed trainees from 6 colleges were chosen by using random sampling method. The data collection instrument for academic self-concept was a researcher made questionnaire. After verifying the scale's factorial structure, established levels of association between self-concept and academic performance, and predictive power of academic self-concept. The research finding showed a close relationship between academic self-concept and measures of academic performance. Academic self-concept powerfully and positive predicts general performance in literature and mathematics. Feel it is necessary to give adequate and sufficient attention to self-concept and self-esteem and teachers should be offered methodological guidance in order to work on these throughout the educational process.
\end{abstract}

\section{INTRODUCTION}

The self-concept is the information that we have about ourselves what we think we are like. Self-concept is persons perceptions of himself formed through experience and interpretations of the environment. Self-concept generally refers to the composite of ideas, feelings, and attitudes people have about themselves. Our self- perceptions vary from situation to situation and from one phase of our lives to another. These perceptions are influenced by a number of factors such as evaluations of significant others, reinforcements, and attributions of behavior. It further refers to the set of perceptions or reference points what the subject has about him: the set of characteristics, attributes, qualities and deficiencies, capacities and limits, values and relationships that subject knows to be descriptive about its own and which he perceives as data concerning his identity.

The multifaceted and hierarchical model of selfconcept suggested that general self-concept has four domains: the academic self-concept, social selfconcept, emotional self-concept and physical selfconcept .The academic self-concept can be divided further into second order specific subject self concepts like Urban, History, Mathematics, and Science etc. which can explain learner achievement in each subject. Social self-concept can be divided into peer self-concept and significant others self-concept. Emotional self concept refers to specific emotional states such as anxiety, love, happiness, depression, and anger. The physical self concept comprises physical ability and physical appearance selfconcepts. The overall sense of self thus appears to be divided into at least three separate, but slightly related, self-concepts i.e. academics, emotional, and nonacademic.

Each one offers insights as to how teachers, can enhance their trainees self-concept. Researchers have been concerned with analyzing of relation- ships, both associative and predictive between self concept and academic performance. For ex- ample, observed that there is a persistent and significant relationship between the self-concept and academic achievement and that change in one seems to be associated with change in the other. Academic self-concept and academic achievement were strongly correlated. Findings of studies conducted on relationship between physical self-concept, social self-concept and 
academic achievement were conflicting. There was no significant correlation between physical appearance and academic achievement and physical activity level was quite an independent entity that was not related to academic achievement. Sports and academic achievement appear to have a mutual influence on each other. There is a negative relation- ship between social self-concept and academic achievement. Academic self concept and academic achievement were best predictors of one another.

Despite the abundance of studies, however, no conclusive picture emerges about the extent of relationship between various self-concepts and academic achievement. It was intended to study the relationship between self-concept and academic achievement in order to rescue those trainees who may be victims of their own negative beliefs about themselves. The study is significant because the results may generate useful knowledge and under- standing of the relationship between the female trainees self concept and academic achievement. The results of the study are likely to assist educators to improve trainees academic achievement and self-concept, if there appears to be some association between the two in country like Pakistan where success rate in education college exams, particularly in women colleges, is considerably low. The study results, therefore, are likely to be significant for trainees, teachers, parents and society at large in order to promote higher education among females. It is a general wish and aspiration of trainees, parents, educators and all stakeholders of education, that trainees and for that matter, learners an all levels of education, excel in their pursuance of academic work at all times. By self, we generally mean the conscious reflection of ones own being or identity, as an object separate from others or from the environment. There are a variety of ways to think about the self. Two of the most widely used terms are self-concept and self-esteem. Self-concept is the cognitive or thinking aspect of self (related to ones selfimage) and generally refers to the totality of a complex, organized, and dynamic system of learned beliefs, attitudes and opinions that each person holds to be true about his or her personal existence. There is a great deal of research which shows that self- concept is, perhaps, the basis for all motivated behaviour. It is the selfconcept that gives rise to possible selves, and it is possible selves that create the motivation for behavior. This supports the idea that ones paradigm or world view and ones relationship to that view provide the boundaries and circumstances within which we develop our vision about possibilities. This is one of the major issues facing trainees and youth today.

Your self-concept is built upon perception upon how you perceive yourself based on the knowledge you have gained over a lifetime of experience. When it comes down to it, a self-concept is a Perception you have of your image, abilities, and in some ways a perception of your own individual uniqueness. This perception you have of your- self is based on the information you have gathered about your values, life roles, goals, skills, and abilities over time. Your self-concept is some- what a collection of beliefs you have about your own nature, qualities, and behavior. Its about how you think and evaluate yourself at any given moment in time. But to truly understand what a self- concept is and its impact on your life, we first need to break down the three components of a self-concept.

The value of having a healthy self- concept becomes more evident when we recognize how much it influences our ability to manage our emotional experiences. However, it doesn't stop there. A healthy self-concept also determines how far you will step outside your comfort zone to solve a problem or achieve a goal. Moreover, it influences how you utilize your physiology while confronting challenges, obstacles, and problems. A healthy self-concept impacts the questions you typically ask yourself each day, and it affects how you interact with people, how you think about yourself, others, and circumstances. Putting all this together, your self-concept effectively determines what you will do or choose not to do at any given moment in time. It, therefore, influences your inherent potential to do, be, have and achieve your desired objectives.

\section{REVIEW OF LITERATURE}

McInerney, D. M., Korpershoek, H., Wang, H.,\& Morin, A. J. (2018) known about the determinants of teachers psychological wellbeing, job satisfaction, occupational self-concept and quitting intentions. In this paper, teachers occupational attributes (i.e. professional and personal characteristics) were investigated as determinants. Hence- forth, the Educator Motivation and Attribute Profile (EdMAP) scales were used to describe the nature of 1109 Hong Kong primary and secondary school teachers occupational attributes. Further- more, the relationships with the teacher outcomes were investigated. Construct validity and reliabilities of the EdMAP scales were satisfactory. The results showed positive associations between teachers occupational attributes and their wellbeing, job satisfaction, and self 
concept, and negative associations with quitting intentions.

Avramidis, E., Avgeri, G., \& Strogilos, V. ((2018) addressed the social participation of integrated students with special educational needs (SEN) in upper primary regular classes in Greece alongside their perceptions of best friend quality. Social participation was defined as consisting of four key dimensions: students acceptance by classmates, friendships, social self-perceptions, and social interactions. Participants were 457 students with a mean age of 11.04 (SD =.83), of which 45 were diagnosed as having moderate learning difficulties. Fieldwork involved implementing a socio metric technique, conducting systematic observations and administering two psychometric instruments: the SelfDescription Questionnaire (SDQ) and the Friendship Qualities Scale (FQS). In line with previous studies, students with SEN KumiYeboah, A., Dogbey, J., \& Yuan, G. (2018) examined factors that promote/hinder the learning experiences and academic self- concept of minority students attending an online high school. Qualitative interviews were con- ducted with twentyfour African American, and sixteen Hispanic high B.Ed Trainees. The results showed that collaborative learning activities, access to resources, time convenience, student- teacher interactions, student-student interactions, improved academic behavior, and parental sup- port helped to enhance online learning experiences and academic self-concept of the minority students. On the contrary, the lack of social presence, and the lack of cultural inclusion in course content constrain online learning experiences and academic self concept of the students. The findings revealed some similarities between factors that influence minority students learning experiences online, and in face- to-face setting. The study also highlighted the need for teachers of online courses to under- stand the cultural backgrounds of minority students, and to use their knowledge to improve the learning experiences and academic selfconcept of these students. Implications for teaching minority high B.Ed Trainees in an online environment, as well as suggestions for future research are provided. Gogol, K., Brunner, M., Mar- tin, R., Preckel, F., \& Gtz, T. (2017). developed comprehensive model of affect and motivation is necessary for disentangling the variance of subject-specific measures into components that are (a) construct-specific and general- ize across different subjects, (b) subject-specific and common to different constructs, and (c) specific to a particular construct in a particular subject. In the present study, we developed and investigated an integrative model that yields new insights concerning the generality and school- subject-specificity of affective-motivational con structs. To this end, we first examined structural models that could account for the hierarchical and subjectspecific nature of academic self-concept, anxiety, and interest, respectively. In a second step, we combined these construct-specific models to investigate an integrative model that was able to simultaneously address between- and within-subject relations. We used data from four large-scale samples of ninth-graders $(\mathrm{N}=$ 8666146) on academic self-concept, interest, and anxiety in three subjects (mathematics, French, and German). Our results underscored the importance of the components at the more global level: The major part of reliable individual differences in subject-specific measures of affective- motivational constructs and their relations to achievement indicators (grades and standardized test scores) was explained by the general components of the affective-motivational constructs and the global affective-motivational appraisals of specific subjects rather than by the construct- and-subjectspecific components. Overall, the structural architecture of the integrative model provides a way to simultaneously analyze complex within- and betweensubject relations of affective-motivational constructs. Turner, H. A., Shattuck, A., Finkelhor, D., \& Hamby, S. (2017) demonstrated the particularly damaging effects of exposure to multiple forms of victimization, or polyvictimization, on youth mental health. The primary objective of the present study is to begin to identify the mechanisms that help ex- plain its powerful impact. Analyses are based on two waves of longitudinal data from the National Survey of trainees Exposure to Violence (NatSCEV), conducted in 2008 and 2010, that comprised a telephone sample of 1,186 youth ages 10 to 17. Using structural equation modeling, we examine direct and indirect effects on distress symptoms of increased, decreased, and stable high poly-victimization between Waves 1 and 2 compared to no or low victimization in both waves. Specifically, we consider the extent to which reductions in core psychosocial resources, including family support, peer support, selfesteem, and mastery, mediate the relation- ship between these poly-victimization conditions and distress. Relative to stable low victimization, both increased poly-victimization and stable high poly-victimization were associated with de- clines in all four resources. However, only self- esteem and mastery significantly mediated the association between poly-victimization and distress, with mastery showing the strongest effect. Although significant indirect effects were evident, polyvictimization still had a strong direct effect on distress 
with resource factors controlled. Findings support the hypothesis that the potent effect of poly-victimization on youth mental health is, in part, due to its damaging influence on core psychosocial resources.

Emmanuel, A. O., Adom, E. A., Josephine, B., \& Solomon, F. K. (2014) investigated the relationship between achievement motivation, academic self concept and academic achievement of high B.Ed Trainees. In addition, the study found out the students profile to ascertain the levels of achievement motivation, selfconcept, and their academic achievement. A total of 120 students selected from four high Colleges participated in the study. The results showed that, majority of the high B.Ed Trainees were highly motivated, have high selfconcept and performed well on the Mathematics Achievement test. The study also found a significant correlation between self-concept and academic achievement. Again, there was a positive relationship between achievement motivation and academic achievement but the correlation was not significant. The study confirms the importance of achievement motivation and academic self- concept to academic achievement and concluded by making insightful suggestions and recommendations to stakeholders in education in helping students to enhance their motivation and self-concept to improve on their academic performance. Preckel, F., Niepel, C., Schneider, M., \& Brunner, M. (2013) Fostering social and academic self-concepts are central educational goals. During mid-adolescence academic engagement and success seem to be devalued by peers and to be negatively associated with students social standing. For this age group, is the development of a positive academic self-concept compatible with the development of a positive social self- concept?. Green, J., Liem, G. A. D., Martin, A. J., Colmar, S., Marsh, H. W., \& McInerney, D. (2012) tested three theoretically/conceptually hypothesized longitudinal models of academic processes leading to academic performance. Based on a longitudinal sample of 1866 high- B.Ed Trainees across two consecutive years of high school (Time 1 and Time 2), the model with the most superior heuristic value demonstrated: (a) academic motivation and self-concept positively predicted attitudes toward school; (b) attitudes toward school positively predicted class participation and homework completion and negatively predicted absenteeism; and (c) class participation and homework completion positively predicted test performance whilst absenteeism negatively predicted test performance. Taken together, these findings provide support for the relevance of the self-system model and, particularly, the importance of examining the dynamic relationships amongst engagement factors of the model. The study highlights implications for educational and psychological theory, measurement, and intervention. Marsh, H. W., \& Martin, A. J. (2011). Academic self concept and academic achievement: Relations and causal ordering. British Journal of Educational Psychology, 81(1), 59-77. A positive self concept is valued as a desirable outcome in many disciplines of psychology as well as an important mediator to other outcomes. The present review examines support for the reciprocal effects model (REM) that posits academic self concept (ASC) and achievement are mutually reinforcing, each leading to gains in the other and its extension to other achievement domains and review the oretical, methodological, and empirical support for the REM. Critical features in this research are a theoretical emphasis on multidimensional perspectives that focus on specific components of self concept and a methodological focus on a construct validity approach to evaluating the REM.

\section{OBJECTIVES OF THE STUDY}

1. To find out the level of study on self concept in relation to academic achievement among B.Ed trainees.

2. To find out the level of study on self concept in relation to academic achievement among B.Ed trainees with respect to gender.

3. To find out the level of study on self concept in relation to academic achievement among B.Ed trainees with respect to locality.

4. To find out the level of study on self concept in relation to academic achievement among B.Ed trainees with respect to medium of study.

5. To find out the level of study on self concept in relation to academic achievement among B.Ed trainees with respect to pedagogy

6. To study the a study on self concept in relation to academic achievement among B.Ed trainees.

7. To develop a questionnaire to assess the impact of self concept on achievement among B.Ed Trainees.

\section{RESEARCH QUESTIONS}

1. Is there any significance mean score difference between gender and level of study on self concept in relation to academic achievement among B.Ed trainees?

2. Is there any significance mean score difference between locality related factors and level of study on 
self concept in relation to academic achievement among B.Ed trainees?

3. Is there any significance mean score difference between medium of study related factors and level of study on self concept in relation to academic achievement among B.Ed trainees?

4. Is there any significance mean score difference between pedagogy and level of study on self concept in relation to academic achievement among B.Ed trainees?

\section{HYPOTHESES}

1. There will be a significant mean score difference between gender and level of study on self concept in relation to academic achievement among B.Ed trainees.

2. There will be a significant mean score difference between locality related factors and level of study on self concept in relation to academic achievement among B.Ed trainees.

3. There will be a significant mean score difference between medium of study related factors and level of study on self concept in relation to academic achievement among B.Ed trainees.

4. There will be a significant mean score difference between pedagogy and level of study on self concept in relation to academic achievement among B.Ed trainees.

\section{VARIABLES}

An independent variable is a variable that is expected to influence the dependent variables. Its value may be changed or altered, which is independent of any other variables. Also the following demographic variables were used as independent variables.

$>$ Gender (Male/Female).

$>$ Locality (Rural/Urban).

$>$ Study Medium (Tamil/English).

$>$ Pedagogy (Arts/Science/Language).

Dependent variable are those events which are by hypothesized as dependent on the changes in the dependent variable (Impact on academic achievement among B.Ed Trainees).

\section{DESIGN OF THE STUDY}

In the presence study normative survey method will be used. Survey research employee questioner and interview to our people who provide information about them selfs their attitude and believes demographic (Age, Gender, Income and So on) the survey method can be classified into many, but according to the objectives and hypotheses in this presence study normative survey method will be adopted.

\section{POPULATION AND SAMPLE}

Coimbatore district is one of the districts in Tamilnadu, India. Coimbatore is finest education district of Tamilnadu. It is the second largest city in Tamilnadu and one of the fastest growing cities in Tamilnadu State. For the present study the investigator selects only 6 Education College in and around Coimbatore. Investigator selected Datas will be collected from the samples of 100 B.Ed Trainees of various Colleges.

\section{SAMPLING TECHNIQUES}

Sampling procedure is a definite plan determined before any data are actually collected for obtaining a sample from/a given population under the simple random sampling technique. This sampling method is used for selecting samples. Simple random sampling is method in which each and every element in the population has an equal chance of getting selected. The study is based on primary data which is collected from 100 school students at higher secondary level and around Coimbatore district. The sample which was collected from various college located in and around Coimbatore is shown as below.

Table1.1 List of Colleges used for data collection

\begin{tabular}{|c|l|l|}
\hline So & \multicolumn{1}{|c|}{ Name of the Colleges } & \multicolumn{1}{|c|}{$\begin{array}{c}\text { Number } \\
\text { of } \\
\text { students }\end{array}$} \\
\hline 1. & $\begin{array}{l}\text { Dr. Sns College of Education, } \\
\text { Coimbatore }\end{array}$ & 16 \\
\hline 2. & $\begin{array}{l}\text { Dr. N.G.P. College of } \\
\text { Education, Coimbatore }\end{array}$ & 14 \\
\hline 3. & $\begin{array}{l}\text { Century Foundation College of } \\
\text { Education }\end{array}$ & 17 \\
\hline 4. & $\begin{array}{l}\text { Hindusthan College of } \\
\text { Education, Coimbatore }\end{array}$ & 18 \\
\hline 5. & $\begin{array}{l}\text { Lisieux College of Education, } \\
\text { Coimbatore }\end{array}$ & 18 \\
\hline 6. & $\begin{array}{l}\text { Rkr College of Education, } \\
\text { Coimbatore }\end{array}$ \\
\hline
\end{tabular}


International Journal of Trend in Scientific Research and Development (IJTSRD) ISSN: 2456-6470

TABLE 1.2

Distribution of samples based on variables

\begin{tabular}{|l|l|l|r|r|}
\hline Category & Subgroups & Number & $\%$ & Total \\
\hline \multirow{3}{*}{ Gender } & Male & 35 & 35 & 100 \\
\cline { 2 - 4 } & Female & 65 & 65 & \\
\hline \multirow{2}{*}{ Locality } & Rural & 63 & 63 & 100 \\
\cline { 2 - 4 } & Urban & 37 & 37 & \\
\hline \multirow{2}{*}{$\begin{array}{l}\text { Medium } \\
\text { Study }\end{array}$} & Tamil & 56 & 56 & \multirow{2}{*}{100} \\
\cline { 2 - 4 } & English & 44 & 44 & \\
\hline \multirow{2}{*}{ Pedagogy } & Language & 48 & 48 & \multirow{2}{*}{100} \\
\cline { 2 - 4 } & $\begin{array}{l}\text { Arts/ } \\
\text { Science }\end{array}$ & 52 & 52 & \\
\hline
\end{tabular}

\section{RESEARCH TOOL}

Tool become another major consideration in an education research. The instrument employed for the collection of data required for the study of any problem is called tool. Tool employ distinction way of describing and qualifying the data the important tools of educational research include inter- view schedule, questionnaire, observation, rating scale, proficiency test, psychological tests and sociogram.

\section{TESTING HYPOTHESIS 1:}

There will be a significant mean score difference in level of study on self concept in relation to academic achievement among B.Ed trainees based on gender (Male/Female).

TABLE 1.3

Mean Score difference and $\mathrm{f}$ - value of factors related to level of study on self concept in relation to academic achievement among B.Ed trainees based on gender

\begin{tabular}{|l|l|l|l|l|l|c|}
\hline $\begin{array}{l}\text { S. } \\
\text { N } \\
\text { o. }\end{array}$ & Gender & N & Mean & Df & $\begin{array}{l}\text { t- } \\
\text { Value }\end{array}$ & $\begin{array}{c}\text { Re- } \\
\text { sult }\end{array}$ \\
\cline { 1 - 4 } 1 & Male & 35 & 1.3856 & \multirow{2}{*}{9} & \multirow{2}{*}{2.051} & S \\
\hline 2 & Female & 65 & 1.6129 & & & \\
\hline \multicolumn{2}{|l|}{ Total } & $\mathbf{1 0 0}$ & $\mathbf{1 . 4 9 9 3}$ & & & \\
\hline
\end{tabular}

The Table 1.3 shows the mean score difference in level of study on self concept in relation to academic achievement among B.Ed trainees based on gender (Male/Female). The calculate $\mathrm{f}$ value is statistically a significance at 0.05 levels and hence the hypotheses 1 is accepted. It can be concluded that there is a significant difference in mean score difference in level of study on self concept in relation to academic achievement among B.Ed trainees based on gender.

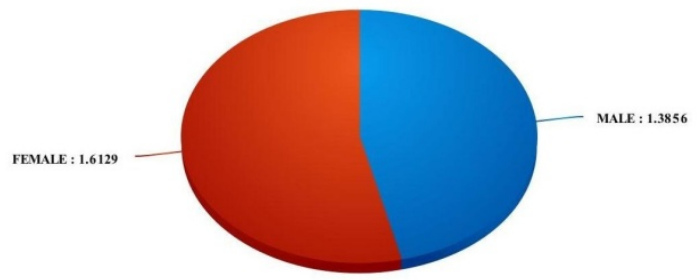

Figure 1: Relationship Between B.Ed Trainees Gender and level of study on self concept in B.Ed Trainees Academic Achievement

\section{TESTING HYPOTHESIS 2:}

There will be a significant mean score difference in level of study on self concept in relation to academic achievement among B.Ed trainees based on Locality(Rural/Urban).

TABLE 1.4 Mean Score difference and t-value of factors related to level of study on self concept in relation to academic achievement among B.Ed trainees based on Locality (Rural/Urban).

\begin{tabular}{|c|c|c|c|c|c|c|}
\hline $\begin{array}{l}\text { S. } \\
\text { N } \\
0 .\end{array}$ & Locality & $\mathrm{N}$ & Mean & $\begin{array}{l}\text { D } \\
\mathrm{f}\end{array}$ & $\begin{array}{c}\mathrm{t}- \\
\text { Value }\end{array}$ & $\begin{array}{l}\text { Re- } \\
\text { sult }\end{array}$ \\
\hline 1 & Rural & 63 & 1.1752 & \multirow{3}{*}{99} & \multirow{3}{*}{$\begin{array}{c}- \\
2.631\end{array}$} & \multirow{3}{*}{$\mathrm{S}$} \\
\hline 2 & Urban & 37 & 1.3562 & & & \\
\hline $\mathrm{C}$ & Total IIC & 100 & 1.2657 & & & \\
\hline
\end{tabular}

The Table 1.4 shows the mean score difference in level of study on self concept in relation to academic achievement among B.Ed trainees based on Locality (Rural/Urban).The calculate $t$ value is statistically a significance at 0.05 levels and hence the hypotheses 2 is accepted. It can be concluded that there is a significant difference in mean score difference in level of study on self concept in relation to academic achievement among B.Ed Trainees based on Locality.

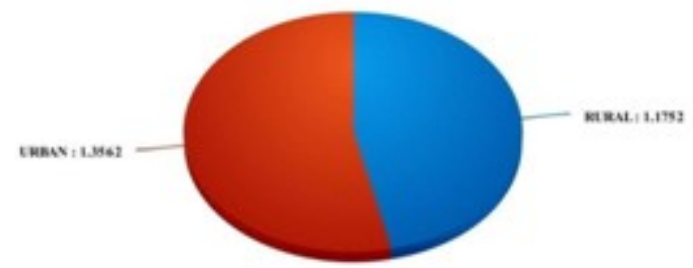

Figure 2: Relationship Between B.Ed Trainees medium of instruction and level of study on self concept in B.Ed Trainees Academic Achievement

\section{TESTING HYPOTHESIS 3:}

There will be a significant mean score difference in level of self concept in relation to academic achievement among B.Ed trainees based on Education study medium (Tamil/English). 
TABLE 1.5: Mean Score difference and t- value of factors related to level of study on self concept in relation to academic achievement among B.Ed trainees based on study medium. (Tamil/English).

\begin{tabular}{|l|l|l|l|l|l|l|}
\hline $\begin{array}{l}\text { S. } \\
\text { N } \\
\text { o }\end{array}$ & $\begin{array}{l}\text { Study } \\
\text { mediu } \\
\text { m }\end{array}$ & N & Mean & Df & $\begin{array}{l}\text { t- } \\
\text { Value }\end{array}$ & $\begin{array}{l}\text { Re } \\
- \\
\text { sul } \\
\text { t }\end{array}$ \\
\cline { 1 - 5 } 1 & Tamil & 56 & 1.2832 & \multirow{2}{*}{9} & \multirow{2}{*}{0.872} & NS \\
\hline 2 & English & 44 & 1.1732 & 99 & & \\
\hline \multicolumn{2}{|l|}{ Total } & $\mathbf{1 0 0}$ & $\mathbf{1 . 1 0 0 2}$ & & & \\
\hline
\end{tabular}

The Table 1.5 shows the mean score difference in level of study among self concept in relation to academic achievement on B.Ed trainees based on Study Medium (Tamil/English).The calculate $t$ value is statistically no significance at 0.05 levels and hence the hypotheses 3 is rejected. It can be concluded that there is no significant differ- ence in mean score difference in level of study on self concept in relation to academic achievement based on Study Medium (Tamil/English).

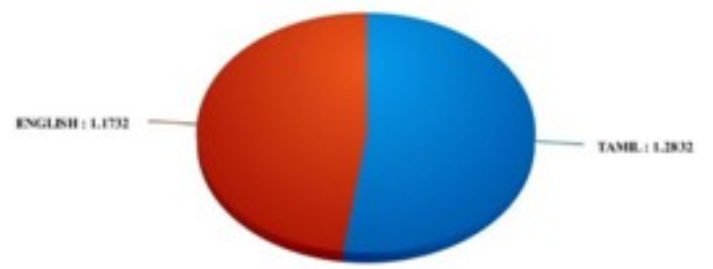

Figure 3:Relationship Between B.Ed Trainees school type and level of study level of study on self concept

in relation to academic achievement among B.Ed trainees Academic Achievement

\section{TESTING HYPOTHESIS 4:}

There will be a significant mean score difference in level of study on self concept in relation to academic achievement among B.Ed trainees based on Pedagogy (Language/Arts/Science).

TABLE 1.6 : Mean Score difference and t- value of factors related to level of study on self concept in relation to academic achievement among B.Ed trainees based on Pedagogy (Language/Arts/Science).

\begin{tabular}{|l|l|l|l|l|l|l|}
\hline $\begin{array}{l}\text { S. } \\
\text { No }\end{array}$ & $\begin{array}{l}\text { Pedag- } \\
\text { ogy }\end{array}$ & N & Mean & Df & $\begin{array}{l}\text { t- } \\
\text { Value }\end{array}$ & $\begin{array}{l}\text { Re } \\
\text { sul } \\
\text { t }\end{array}$ \\
\hline 1 & $\begin{array}{l}\text { Lang- } \\
\text { uage }\end{array}$ & 48 & 1.4121 & & & \\
\cline { 1 - 5 } & $\begin{array}{l}\text { Arts/ } \\
\text { Science }\end{array}$ & 52 & 1.0891 & 99 & -2.325 & $\begin{array}{l}\mathbf{N} \\
\mathbf{S}\end{array}$ \\
\hline \multicolumn{2}{|l|}{ Total } & & $\mathbf{1 0 0}$ & $\mathbf{1 . 2 5 0 6}$ & & \\
\hline
\end{tabular}

The Table 1.6 shows the mean score difference in level of study on self concept in relation to academic achievement among B.Ed trainees based on Pedagogy (Language/Arts/Science).The calculate $\mathrm{t}$ value is statistically a significance at 0.05 levels and hence the hypotheses 4 is accepted. It can be concluded that there is a significant difference in mean score difference in level of study on self concept in relation to academic achievement based on Pedagogy (Language/Arts/Science).

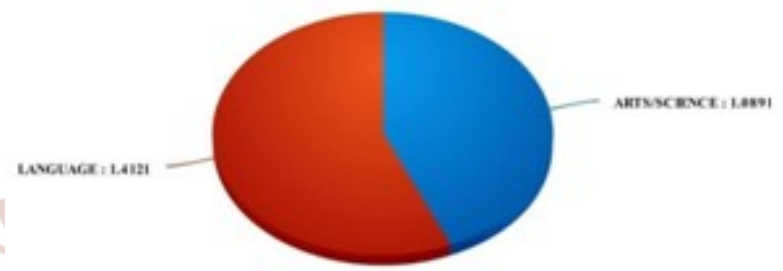

Figure4.3: Relationship Between B.Ed Trainees school location and level of study level of study on self concept in relation to academic achievement among B.Ed trainees

\section{FINDINGS OF THE STUDY}

$>$ There is a significant relationship between gender and level of study on self concept in relation to academic achievement among B.Ed trainees.

There is a significant relationship between medium of instruction related factors and level of study on self concept in relation to academic achievement.

There is no significant relationship between pedagogy related factors and impact of self concept in relation to academic achievement among B.Ed trainees.

$>$ There is a significant relationship between school location and level of study on self concept in relation to academic achievement among B.Ed trainees.

\section{SUMMARY}

$>$ A study of self concept among B.Ed Trainees academic achievement was studied and the findings reveal that there is a significant difference with respect to gender, Locality and medium of study.

$>$ A study of self concept among B.Ed Trainees academic achievement was studied and the findings reveal that there is no significant difference between level of study on higher secondary commerce students academic achievement with respect to Pedagogy.

\section{LIMITATIONS}


$>$ The study has certain limitation, which are as follows:

$>$ - Only 100 B.Ed are selected as sampling for the study.

$>$ The project has been restricted to analyze and study of self concept academic achievement among B.Ed Trainees.

$>$ The study is restricted to the B.Ed Trainees of Coimbatore.

\section{CONCLUSION \\ AND FUTURE \\ RECOMMENDATIONS}

$>$ A Similar Study can be conducted for dissertation by taking more number of concepts and students.

$>$ The study can be conducted to other Colleges around Tamilnadu.

$>$ Present survey helps to investigate the impact level of self concept of B.Ed Trainees for academic achievement.

$>$ A similar study can also be conducted using various variables.

The conclusion is that there is a significant relationship between gender, locality and pedagogy on impact of self concept among B.Ed Trainees While taking decision on impact of self/concept among B.Ed Trainees their pedagogy and locality has to be taken for decision making process.

\section{BIBLIOGRAPHY}

1. Aggarwal, S., \& Berk, M. (2015). Evolution of adolescent mental health in a rapidly changing socioeconomic environment: A review of mental health studies in adolescents in India over last 10 years. Asian journal of psychiatry, 13, 3-12.

2. Anitha, J., \& Parameswari, G. (2013). Cor- relates of self-concept among high B.Ed Trainees in Chennai City, Tamilnadu, India. International Journal of Current Research and Academic Review, 1(4), 30-34.

3. Avramidis, E., Avgeri, G., \& Strogilos, V. (2018). Social participation and friendship quality of students with special educational needs in regular Greek primary schools. European Journal of Special Needs Education, 1-14.

4. Chaudhary, N., Kapoor, S., \& Negi, B. (2018). Individual Achievement and Social Progress: Mending the Broken Alliance between School and the Community in India. In Alterity, Values, and Socialization (pp. 65-86). Springer, Cham.
5. Cheung, D. (2018). the key factors affecting students individual interest in school science lessons. International Journal of Science Education, 40(1), 1-23.

6. Deb, S., Strodl, E., \& Sun, J. (2014). Academicrelated stress among private secondary B.Ed Trainees in India. Asian Education and Development Studies, 3(2), 118-134.

7. Salchegger, S. (2016). Selective school systems and academic self-concept: How explicit and implicit school-level tracking relate to the bigfish-little-pond effect across cultures. Journal of Educational Psychology, 108(3), 405.

8. Satheesan, S., \& Hameed, N. (2018). Gen- der differences in developmental assets profile of college going youth: a report from India. International Journal Of Community Medicine And Public Health, 5(2), 714-720.

9. Shazadi, T., Khatoon, S., Aziz, S., \& Hassan, H. (2011). Determining Factors Affecting Teachers SelfEfficacy at Secondary School Level. Language in India, 11(10).

10. Shekhar, C., \& Devi, R. (2012). Achievement motivation across gender and different academic majors. Journal of Educational and Developmental Psychology, 2(2), 105.

11. Sumantri, M. S., \& Wardhani, P. A. (2018). The Influence of Competence and Self-confidence on Elementary School Teacher Performance. In Educational Technology to Improve Quality and Access on a Global Scale (pp. 309-320). Springer, Cham.

12. Vyas, S., \& Choudhary, G. (2017). Relationship of socio economic status with frustration, selfconcept, study habits and academic achievement of adolescents (Book).

\section{APPENDICES}

\section{PROFORMA FOR BASIC DATA}

1. Name of the student :

2. Name of the Education College :

3. Gender : Male [ ] Female [ ]

4. Locality : Rural [ ] Urban [ ]

5. Study Medium : Tamil [ ] English [ ]

6. Pedagogy : Language [ ] Arts/Science [ ] 
QUESTIONNAIRE

\begin{tabular}{|c|c|c|c|}
\hline 1 & In your view, has self concept ever used for academic achievement? & Yes & No \\
\hline 2 & Has self concept ever used for the learning of any of your family or friends? & Yes & No \\
\hline 3 & Apart from self concept, are you aware different self learning activities? & Yes & No \\
\hline 4 & Do you feel the way of learning is generally changing in recent years? & Yes & No \\
\hline 5 & Have you heard of "Everyone is Unique"? & Yes & No \\
\hline 6 & $\begin{array}{l}\text { Do you think individual skills are something that is helping or is going to improve, } \\
\text { Personally? }\end{array}$ & Yes & No \\
\hline 7 & Do you think anything can be done to improve Self learning skills? & Yes & No \\
\hline 8 & Have your ever taken, or do you regularly take, any steps for self improvement? & Yes & No \\
\hline 9 & Is trainees already aware of self concept? & Yes & No \\
\hline 10 & Is there anything self learning help us in Knowledge gaining? & Yes & No \\
\hline 11 & Will learn through self learning be affect our personality? & Yes & No \\
\hline 12 & Would a Self learning really change the academic achievement level of B.Ed Trainees? & Yes & No \\
\hline 13 & Are self concept taught more than books? & Yes & No \\
\hline 14 & Can self concept really essentials for B.Ed trainees in future? & Yes & No \\
\hline 15 & Can self concept lead to better teaching? & Yes & No \\
\hline 16 & Will self concept actually bring obstruction to some trainees? & Yes & No \\
\hline 17 & Could self concept ever "Complex process"? & Yes & No \\
\hline 18 & Have the Knowledge from self concept useful in exams? & Yes & No \\
\hline 19 & Is there formal way of self concept is under way? & Yes & No \\
\hline 20 & Are you concerned about self learning? nátiotial vourtial & Yes & No \\
\hline 21 & Are you aware of the impacts of self learning? in ce ientific & Yes & No \\
\hline 22 & Are you aware of the causes and effects of self learning? & Yes & No \\
\hline 23 & Do trainees also share their learning with others through self learning? & Yes & No \\
\hline 24 & Couldn't the usage of technology cause the self learning? & Yes & No \\
\hline 25 & Don't trainees learn more ideas from self learning than textbooks? & Yes & No \\
\hline 26 & Hasn't education system improved or demoted after self learning adaptation? & Yes & No \\
\hline 27 & Are there positive benefits from self learning? $\angle 400=04 / 0$ & Yes & No \\
\hline 28 & Can we pay additional fee for self concept? & Yes & No \\
\hline 29 & Are practical approaches are missed in self concept? & Yes & No \\
\hline 30 & Will self concept cause the limited learning opportunities? & Yes & No \\
\hline
\end{tabular}

